\title{
Maternal occupation in the leather industry and selected congenital malformations
}

\author{
Ana M García, Tony Fletcher
}

\begin{abstract}
Objectives-Data from a hospital based case-control study were analysed to assess the relation between maternal occupation in the leather industry and several groups of congenital defects (nervous system, cardiac defects of closure, oral cleft, epispadia or hypospadia, and multiple anomalies).

Methods-Cases and controls were selected from eight public hospitals in Comunidad Valenciana, Spain, in 1993 and 1994. Cases were located from the hospital discharge records, including children born and diagnosed in some of the selected hospitals during their first year of life. Controls were selected from births without congenital defects in the same hospitals and dates of the cases (ratio 1:1). Both parents of selected children were interviewed (mainly by phone) and information about potential confounding variables and occupational history during the three years before the birth was collected in structured questionnaires.
\end{abstract}

Results-A total of 261 cases and the same number of controls were included in the study. Adjusted odds ratios (ORs) were estimated for maternal occupation in the leather industry in the period between three months before the conception and the birth of the child $(n=22)$, and each selected group of congenital malformations: nervous system defects (OR 1.02, $95 \%$ confidence interval $(95 \%$ CI) 0.12 to 8.51), cardiac defects of closure (OR 1.78, $95 \%$ CI 0.44 to 7.17 ), oral clefts (OR 6.18, $95 \%$ CI 1.48 to 25.69 ), for epispadia or hypospadia (OR 4.05, 95\% CI 0.77 to

Department of Preventive Medicine and Public Health, University of Valencia, Spain

A M García

Environmental Epidemiology Unit, Department of Public Health and Policy, London School of Hygiene and Tropical Medicine, UK

$\mathrm{T}$ Fletcher

Accepted 25 November 1997
(Occup Environ Med 1998;55:284-286)

Keywords: leather industry; maternal occupation; congenital malformations

Bianchi et $a l^{1}$ have recently investigated the relation between maternal occupation in four groups (health service carers, hairdressers, textile dye workers, and leather workers) and congenital malformations in a registry based casecontrol study. They found an increase of the risk for oral clefts in mothers involved in the leather and shoe manufacturing industry during pregnancy (adjusted odds ratio (OR) 3.9, $99 \%$ confidence interval (99\% CI) $1.5-9.8$ ). The authors considered that these workers are likely to be exposed to organic solvents, and the relation between this exposure and congenital defects was discussed.

We have recently carried out a case-control study on exposure to pesticides and congenital malformations in Comunidad Valenciana, a region of Spain. In this study, information about maternal occupational history was collected. In this report we present the analysis of the relation between maternal occupation in the leather industry and selected congenital malformations.

\section{Methods}

Cases and controls were selected from births in eight public hospitals serving the main intensive agricultural zones in Comunidad Valenciana during the period between 1 January 1993 and 31 December 1994. Malformations included in the study were nervous system defects (international classification of diseases ninth revision (ICD-9) 740.0-742.9), cardiovascular defects (ICD-9 745.0-747.9 excluding code 746.9), oral clefts (ICD-9 749.0749.2), epispadia or hypospadia (ICD-9 752.6), and musculoskeletal defects (ICD-9 754.0-756.9 excluding code 754.3). Children with more than one defect from different groups were classified as having multiple anomalies. Cases were identified from the hospitals' discharge records. Only children up to one year of age and born and diagnosed during the study period were included. Controls were obtained from births occurring in the same hospitals and matched on date of birth with a ratio of $1: 1$. Controls were not malformed children, and as sure in leather industries, probably in relation to solvents, would be justified. 
Maternal occupation as assembler in the leather industry and selected groups of congenital malformations

\begin{tabular}{|c|c|c|c|c|}
\hline & Exposed ${ }^{*} t$ & Unexposed & Crude OR (95\% CI) & Adjusted OR (95\% CI) \\
\hline $\begin{array}{l}\text { Nervous system defects } \\
\text { (ICD-9 740.0-742.0) }\end{array}$ & 1 & 35 & $\begin{array}{l}0.88 \\
(0.11 \text { to } 7.27)\end{array}$ & $\begin{array}{l}1.02 \ddagger \\
(0.12 \text { to } 8.51)\end{array}$ \\
\hline $\begin{array}{l}\text { Cardiac defects of closure } \\
\text { (ICD-9 745.0-745.9) }\end{array}$ & 3 & 57 & $\begin{array}{l}1.63 \\
(0.42 \text { to } 6.32)\end{array}$ & $\begin{array}{l}1.78 \int \\
(0.44 \text { to } 7.17)\end{array}$ \\
\hline $\begin{array}{l}\text { Oral cleft } \\
\text { (ICD-9 749.0-749.2) }\end{array}$ & 3 & 15 & $\begin{array}{l}6.18 \\
(1.48 \text { to } 25.69)\end{array}$ & $\begin{array}{l}6.18 \text { व } \\
\text { (1.48 to } 25.69)\end{array}$ \\
\hline $\begin{array}{l}\text { Hypo/epispadia } \\
\text { (ICD-9 752.6) }\end{array}$ & 2 & 16 & $\begin{array}{l}3.86 \\
(0.76 \text { to } 19.70)\end{array}$ & $\begin{array}{l}4.05^{\star \star} \\
(0.77 \text { to } 21.44)\end{array}$ \\
\hline Multiple anomalies & 4 & 31 & $\begin{array}{l}3.98 \\
(1.13 \text { to } 14.00)\end{array}$ & $\begin{array}{l}3.14+\dagger \\
(0.82 \text { to } 12.00)\end{array}$ \\
\hline Controls & 8 & 247 & - & - \\
\hline
\end{tabular}

^Nine mothers ( 6 control mothers and 3 case mothers) working as assemblers in the leather industry before the time of interest were excluded from this analysis.

†Some exposed cases did not belong to any of the groups of malformations in this table; a case can be included in more than one group.

$\ddagger$ Controlling by maternal drug consumption (other than supplements—-for example, vitamins or trace elements) during pregnancy and paternal age $>40$ years.

\$Controlling by maternal previous history of spontaneous abortion, twins in index pregnancy, maternal drug consumption (other than supplements) during pregnancy, maternal heavy smoking during first trimester of pregnancy ( $>15$ cigarettes/day), and paternal occupation as industrial worker.

TSame as univariate model: no other terms met the criteria for inclusion

$\star \star$ Controlling by maternal drug consumption (other than supplements) during pregnancy.

††Controlling by maternal previous history of spontaneous abortion, maternal heavy smoking during first trimester of pregnancy ( $>$ 15 cigarettes/day), and paternal occupation as industrial worker.

for the cases, were selected among live births. The analysis presented in this report has been limited to those groups of defects previously related to occupation in the leather industry or occupational exposure to solvents.

The parents of the children were located and interviewed by phone or by face to face interviews when a phone number was not available. Interviews were carried out by trained interviewers blinded towards disease status of the selected children. The maximum period between interviews and the birth of the selected child was around two years. For each parent, information was obtained on the occupational history during the three years before the birth of the selected child, including the activity of the industry or company where they had been working, a short description of their usual job or tasks, and dates of starting and leaving the job. Occupations were firstly classified in broad categories, and within the category of production workers the only work in the leather industry was assembly work in shoe and belt manufacture. The assignment of occupational categories was made by one of us (AMG), blind to disease status. Mothers engaged in such work in the period between three months before the conception and the birth of the selected child were considered to be exposed.

Information on potential confounding variables for each parent was collected as well (age, tobacco, consumption of alcohol and drugs, medical history, close family health, socioeconomic data, and for the mother the reproductive history including problems during the study pregnancy). As there were many potential confounding variables, the first selection of variables to be included in the multivariate models was based on the general distribution of the variable, its statistical association with disease status, and its postulated relevance to the hypothesis under study. Subsequently, selected maternal and paternal confounders were simultaneously considered in saturated multivariate models and kept or dropped from these models according to $\mathrm{p}$ val- ues for the likelihood ratio test between models with and without each variable.

Mothers working as assemblers in the leather industry during the period of interest were considered to be exposed and compared with all the other mothers - the (non-exposed) control category. Crude and adjusted odds ratios (ORs) and $95 \%$ confidence intervals (95\% CIs) were calculated from univariate and multivariate unconditional logistic regression models.

\section{Results}

The 292 cases and 284 controls were selected and their parents located to carry out the interviews. From them, the father or the mother of 31 cases $(11 \%)$ and 23 controls $(8 \%)$ refused to be interviewed $(p=0.30)$. A total of 261 cases and the same number of controls were finally included in the study.

In our sample there was a total number of 22 mothers who were working in the leather industry as assemblers, most of them in shoe factories $(n=20)$, in the period between three months before the conception and the birth of the child. The table presents the ORs and 95\% CIs for maternal occupation in the leather industry and selected groups of congenital malformations.

\section{Discussion}

The relation between maternal occupational exposure to solvents and congenital malformations has been investigated in previous studies, with several significant positive associations reported although the category of birth defect is not consistent. ${ }^{2}$ In an influential work, Holmberg and Nurminen ${ }^{3}$ reported an association between maternal occupational exposure to solvents and defects of the central nervous system. In a later work by the same group, ${ }^{4}$ an additional association with oral cleft was reported. McDonald et a $\bar{l}$ found an association between maternal occupational exposure to aromatic solvents (mainly toluene) and genitourinary defects. A weak association between maternal exposure to organic solvents and ventricular septal defects has been reported as 
well, ${ }^{6}$ and the authors pointed out that, as with oral clefts and neural tube defects, these anomalies are failures in closure. Cordier et al found increased risks for maternal occupational exposure to organic solvents and oral cleft and digestive defects and multiple anomalies. ${ }^{7}$

We consider that our data provide support for the finding by Bianchi et $a l^{1}$ of an increased risk of oral cleft in the offspring after maternal occupation in the leather industry. The association between exposure to solvents and oral cleft defects has been found in other previous studies ${ }^{4}$ although available evidence for other defects seems more contradictory. These findings justify some precautionary recommendations about maternal exposure in leather industries. As leather workers could be exposed to different substances and chemical classes, ${ }^{8}$ additional research to identify the specific exposure potentially related to the increase of the risk is required.
1 Bianchi F, Cianciulli D, Pierini A, et al. Congenital malformations and maternal occupation: a registry based case-control study. Occup Environ Med 1997;54:223-8.

2 Lindbohm ML. Effects of parental exposure to solvents on pregnancy outcome. f Occup Environ Med 1995; 37:90814.

3 Holmberg PC, Nurminen M. Congenital defects of the central nervous system and occupational factors during pregnancy. A case-referent study. Am f Ind Med 1980;1: pregnancy.
$167-76$.

4 Kurppa K, Holmberg PC, Hernberg S, et al. Screening for occupational exposures and congenital malformations. Scand $\mathcal{f}$ Work Environ Health 1983;9:89-93.

5 McDonald JC, Lavoie J, Cote R, et al. Chemical exposures at work in early pregnancy and congenital defect: a case-referent study. Br f Ind Med 1987;44:527-33.

6 Tikkanen J, Heinonen OP. Maternal exposure to chemical and physical factors during pregnancy and cardiovascular malformations in the offspring. Teratology 1991;43:591600.

7 Cordier S, Ha MC, Ayme S, et al. Maternal occupational exposure and congenital malformations. Scand $\mathcal{f}$ Work Environ Health 1992;18:11-7.

8 Miligi L, Scarpelli A, Seniori Constantini A, et al. Comparison of methods of occupational exposure assessment in epidemiology: solvents in shoe and leather goods industries. In: Conference on Retrospective Assessment of Occupational Exposures in Epidemiology [programme and abstracts]. Lyon: International Agency for Research on Cancer, 1994:122.

\section{Occupational and Environmental Medicine and the electronic age}

OEM has an Email address which is 100632.3615@compuserve.com. We welcome contact by Email, including letters to the editor. Many of our reviewers send us their reports by Email, helping to speed up the peer review process.
Our publishing system is now fully electronic, and authors are sending their revised copy to us on disk as well as paper. Watch for revised Instructions to Authors.

The Editor 